http://jmscr.igmpublication.org/home/ ISSN (e)-2347-176x ISSN (p) 2455-0450 crossref DOI: https://dx.doi.org/10.18535/jmscr/v7i12.129

\title{
Comparative Study of Intrathecal Hyperbaric 0.5\% Bupivacaine and Hyperbaric 0.5\% Bupivacaine with Low Dose Dexmedetomidine in Lower Limb Orthopaedic Surgeries
}

\author{
Authors \\ Sree Vidya Ramineedi ${ }^{1}$, Kalyan Chakravarthy $\mathbf{P}^{2}$, Hemnath Babu $\mathbf{K}^{3}$, \\ Rekha P A L ${ }^{4}$, Preethi $\mathbf{V}^{5}$ \\ ${ }^{1}$ Post graduate, Department of Anaesthesiology GEMS \\ ${ }^{2}$ Professor, Department of Anaesthesiology GEMS \\ ${ }^{3}$ Associate Professor, Department of Anaesthesiology, GEMS \\ ${ }^{4,5}$ Postgraduates, Department of Anaesthesiology GEMS
}

\begin{abstract}
Background: Spinal anaesthesia is the preferred technique for lower limb surgeries due to its early onset of action, superior level of blockade and with a reduction of failure rate. Intrathecal a2-agonists, dexmedetomidine used as an adjuvant drug to local anaesthetics potentiate the effect of local anaesthetics and allow decrease in the required doses. In the present study, we evaluated the efficacy of intrathecal $0.5 \%$ heavy bupivacaine alone with Dexmedetomidine as an adjuvant to intrathecal $0.5 \%$ heavy bupivacaine for elective lower limb orthopaedic surgeries.

Material and Methods: A total of 60 patients were involved in prospective, randomised, observational study in department of anaesthesiology, who are scheduled for elective lower limb orthopaedic surgeries at Great Eastern Medical School and hospital. Patients belonging to ASA grade I and II were included in the study. Patients were randomly allocated into 2 groups. Each group consisted of 30 patients having Group-B as Control group which received 0.5\% hyperbaric bupivacaine 3cc (15 mg) and Group-BD which received $0.5 \%$ hyperbaric bupivacaine $3 c c(15 \mathrm{mg})+10 \mu \mathrm{g}$ Dexmedetomidine.

Results: In the present study we found that in Dexmedetomidine group time to reach T10 sensory blockade, complete motor blockade was earlier, duration of motor blockade and duration of analgesia was significantly prolonged in comparison to the control group. Hemodynamic parameters were observed both intra-operatively and postoperatively. However there were a few patients who developed hypotension and Bradycardia who were easily managed without any untoward effect.

Conclusion: It can be concluded that intrathecal low dose Dexmedetomidine in the dose of $10 \mu \mathrm{g}$ along with 3 cc 0.5\% hyperbaric bupivacaine, lead to an earlier onset and prolonged duration of sensory and motor blockade, excellent postoperative analgesia, with minimal adverse effects and stable hemodynamic conditions.

Keywords: Spinal anaesthesia, Dexmedetomidine, hyperbaric 0.5\% Bupivacaine.

\section{Introduction}

Peri operative pain management is a significant challenge for anaesthesiologist. Attenuation of the

postoperative pain may decrease peri operative morbidity and mortality. ${ }^{[1]}$ By optimizing postoperative analgesia, we can reduce postoperative complications and facilitate recovery
\end{abstract}


during immediate postoperative period and early discharge of the patients. Spinal anaesthesia is the preferred technique for lower limb surgeries due to its early onset of action, superior level of blockade and with a reduction of failure rate. ${ }^{[2]}$ Relatively short duration of action of local anaesthetic injected intrathecally needs early analgesic intervention in postoperative period or use of intrathecal adjuvant to local anaesthetic. ${ }^{[3]}$ Many drugs like fentanyl, midazolam, ${ }^{[4]}$ neostigmine, ketamine, clonidine, dexmedetomidine have been used as an additive to local anaesthetic in spinal anaesthesia to prolong the duration of action and to provide adequate postoperative analgesia. Intrathecal a2-agonists, dexmedetomidine ${ }^{[5]}$ used as adjuvant drugs to local anaesthetics potentiate the effect of local anaesthetics and allow a decrease in the required doses. Intravenous Dexmedetomidine results in a significant opioid-sparing effect, intravenous sedative and co analgesic drug as well as a decrease in inhalational anaesthetic requirements. ${ }^{[6],[7]}$

In present study, we tried to study effectiveness of intrathecal $0.5 \%$ heavy bupivacaine alone with Dexmedetomidine as an adjuvant to intrathecal $0.5 \%$ heavy bupivacaine for elective lower limb orthopaedic surgeries.

\section{Material and Methods}

A total number of 60 patients were involved in prospective, randomized, observational study conducted in department of Anaesthesiology, who are scheduled for elective lower limb orthopaedic surgeries at Great Eastern Medical School and Hospital. Patients were randomally allocated into 2 groups. Each group consisted of 30 patients having Group-B (Control group) which received 0.5\% hyperbaric bupivacaine $3 \mathrm{cc}(15 \mathrm{mg})$

Group-B D (study group) which received $0.5 \%$ hyperbaric bupivacaine $3 \mathrm{cc} \quad(15 \mathrm{mg})+10 \mu \mathrm{g}$ Dexmedetomidine.

\section{Inclusion Criteria}
1. American Society of Anaesthesiologist physical status I/ II
2. Either sex
3. Age between 18 to 60 years

\section{Exclusion Criteria}

Patients having history of uncontrolled hypertension, ischemic heart disease, local skin site infection, previous spine surgeries, any kind of bleeding disorders, height $<150 \mathrm{~cm}$.

A through preoperative evaluation by anaesthesiologist of all the patients was done after obtaining the institutional ethical committee clearance. All patients were kept nil per oral overnight and pre-medicated on the previous night of surgery with oral tablet alprazolam $0.5 \mathrm{mg}$. On arrival in the operating room, Intravenous (IV) access was obtained on the non dominant hand with 18-gauge cannula, patients were preloaded with lactated ringer's solution at $15 \mathrm{ml} / \mathrm{kg}$. All patients were monitored with automated non-invasive blood pressure, pulse oximetry and electrocardiogram. Spinal needles used were either 23 or 25 gauge pencil point needles and were introduced at L3-4 or L4-5 interspace in sitting position with all aseptic precautions. Time to reach T10 sensory level, time to reach maximum motor block, duration of motor block, duration of analgesia, haemodynamic parameters (HR,MAP), side effects were studied Motor blockade was assessed using modified Bromage scale.

0 - Full flexion of knee and feet

1 - Inability to raise extended leg, able to move knee and feet

2 - Inability to raise extended leg and move knee, able to move feet

3 - Complete block of lower limb.

\section{Results}

Demographic data

\begin{tabular}{|lccc|}
$\begin{array}{l}\text { Demographic } \\
\text { data }\end{array}$ & Group B & Group BD & $\begin{array}{c}\text { p } \\
\text { value }\end{array}$ \\
\hline Age (yrs) & $41.44 \pm 8.39$ & $40.72 \pm 8.44$ & 0.670 \\
\hline Weight (kgs) & $62.58 \pm 744$ & $61.68 \pm 7.16$ & 0.552 \\
\hline Height (cms) & $159.26 \pm 7.29$ & $161.62 \pm 7.93$ & 0.125 \\
\hline $\begin{array}{c}\text { Gender } \text { - Male } \\
\text { Female }\end{array}$ & $18(60 \%)$ & $19(63.3 \%)$ & 0.7 \\
\hline
\end{tabular}

The two groups analysed were similar in terms of demographic profile including patients' age, sex, weight and height with no statistically significant difference 
Spinal block characteristics

\begin{tabular}{|lccc|}
\hline $\begin{array}{l}\text { Spinal block } \\
\text { characteristics }\end{array}$ & Group B & Group BD & $\begin{array}{c}\text { P } \\
\text { value }\end{array}$ \\
\hline $\begin{array}{l}\text { Time to reach T 10 } \\
\text { sensory block }\end{array}$ & $4.39 \pm 1.14$ & $2.72 \pm 1.02$ & $<0.001$ \\
\hline $\begin{array}{l}\text { Time required for } \\
\text { maximum motor } \\
\text { blockade }\end{array}$ & $8.13 \pm 1.25$ & $4.86 \pm 1.11$ & $<0.001$ \\
\hline $\begin{array}{l}\text { Duration of motor } \\
\text { block }\end{array}$ & $168.71 \pm 9.3$ & $262.28 \pm 17.43$ & $<0.001$ \\
\hline Duration of analgesia & $203.4 \pm 12.52$ & $362.23 \pm 26.57$ & $<0.001$ \\
\hline
\end{tabular}

In Dexmedetomidine group time to reach T10 sensory blockade and complete motor blockade was earlier compared to control group achieved. Duration of, motor blockade and duration of analgesia was significantly prolonged in the Dexmedetomidine group compared to the control group.

\section{Mean PR at various duration}

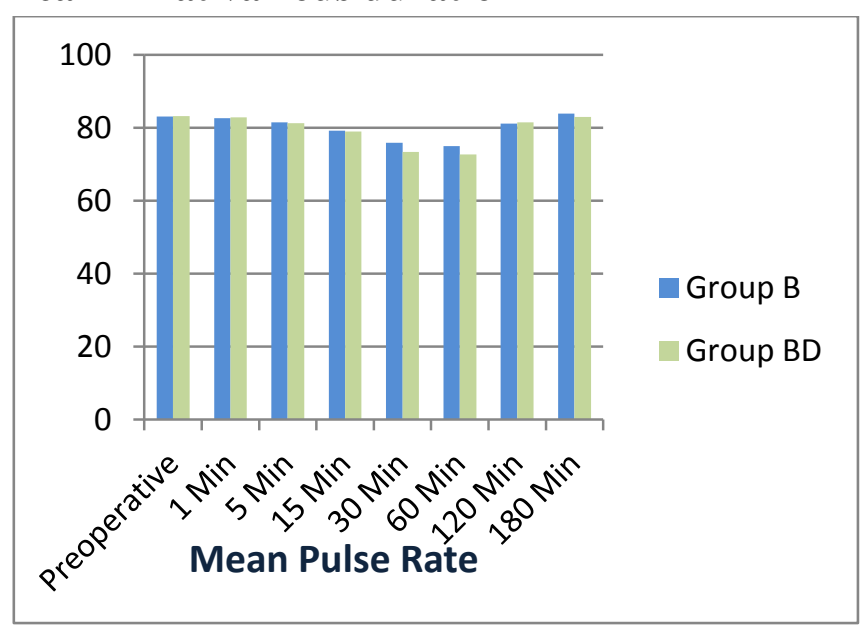

There is no significant difference between mean pulse rate in group B and group BD. Maximum fall in mean pulse rate was seen during 15 minutes to 60 minutes in both group and was both statistically and clinically insignificant.

\section{Mean MAP at various duration}

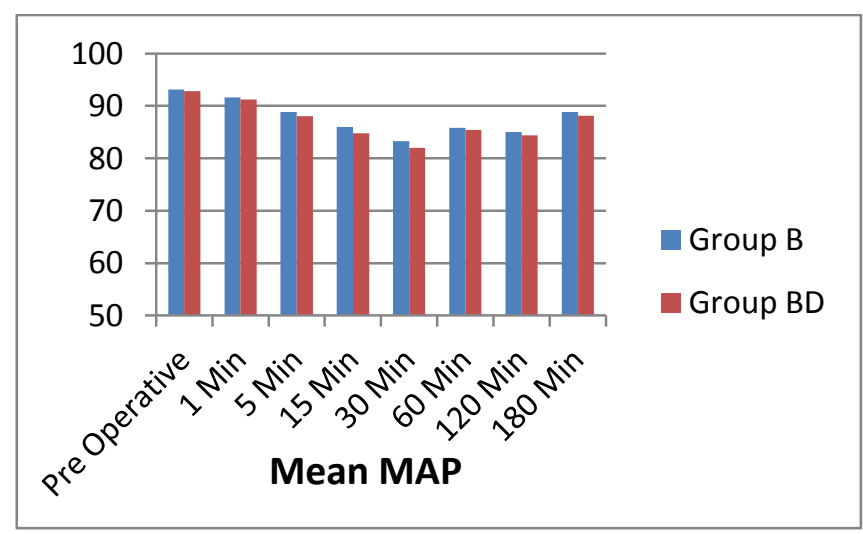

There is no significant difference between mean pulse rate in group B and group BD. Maximum fall in mean pulse rate was seen during 15 minutes to 30 minutes in both group and was both statistically and clinically insignificant.

\section{Side Effects}

\begin{tabular}{|l|c|c|}
\hline Side effects & $\begin{array}{c}\text { Group B } \\
(\mathrm{N}=30)\end{array}$ & $\begin{array}{c}\text { Group BD } \\
(\mathrm{N}=30)\end{array}$ \\
\hline Hypotension & $2(6.6 \%)$ & $3(10 \%)$ \\
\hline Bradycardia & $1(3.3 \%)$ & $2(6.6 \%)$ \\
\hline Nausea & 0 & $1(3.3 \%)$ \\
\hline
\end{tabular}

Hypotension occurred in two patients in Group B and three patients in Group BD and required vasopressors and additional fluids. Thus more patients required additional fluid and vasopressors in Group BD as compared to patients in Group B. One patient in Group B required Inj. Atropine for bradycardia while two patients in Group BD required treatment for bradycardia. Nausea was experienced by only one patient in Group BD while no patients in Group B experienced.

\section{Discussion}

Spinal anaesthesia is the preferred technique for lower abdominal, perineal and lower limb surgeries due to its rapid onset of action, less failure rate and superior level of blockage. ${ }^{[2]}$ Intrathecal a2agonists, dexmeditomidine used as adjuvant drugs to local anaesthetics potentiate the effect of local anaesthetics and allow a decrease in the required doses. $^{[5]}$ It is eight times more alpha-2 selective than Clonidine, producing faster onset and significantly longer duration of analgesia than bupivacaine alone, when used as an adjuvant. ${ }^{[8]}$

It was found from present study that in Dexmedetomidine group time to reach T10 sensory blockade and complete motor blockade was earlier and a higher level of sensory blockade compared to control group achieved. Duration of motor blockade and duration of analgesia was significantly prolonged in the Dexmedetomidine group compared to the control group. Safiya Shaikh and colleagues used $5 \mu \mathrm{g}$ and $10 \mu \mathrm{g}$ dexmedetomidine with placebo as an adjuvant to hyperbaric bupivacaine and found 
that $10 \mu \mathrm{g}$ dexmedetomidine was a better adjuvant with hyperbaric bupivacaine. ${ }^{[9]}$ This is similar to our study

Hemodynamic parameters were observed both intraoperatively and postoperatively. However there were a small percentage of patients who developed hypotension and bradycardia which were easily managed without any untoward effect. Three patients in Dexmedetomidine group and two patients in control group developed hypotension requiring treatment. Two patients in Dexmedetomidine group and one patient in control group developed bradycardia requiring treatment. Dexmedetomidine causes activation of central postsynaptic $\alpha 2$ adrenoreceptor resulting in sympatholytic effects leading to bradycardia and hypotension. Sherif Abdelhemid ${ }^{[10]}$ et al in their study showed that there was difference in heart rate and blood pressure was statistically significant at 10 , 15, 20, 30 min but clinically insignificant. They also studied that, dexmedetomidine causes minimal side effects and prolong postoperative analgesia, Our results were consistent to above study.

\section{Conclusions}

It can be concluded that intrathecal low dose Dexmedetomidine in the dose of $10 \mu \mathrm{g}$ along with 3 cc $0.5 \%$ hyperbaric bupivacaine, lead to an earlier onset and prolonged duration of sensory and motor blockade, excellent postoperative analgesia, with minimal adverse effects and stable hemodynamic conditions.

\section{References}

1. Kehlet H, Holte K. Effect of postoperative analgesia on surgical outcome. Br J Anaesth. 2001;87(1):62-72.

2. Davis NJ, Cashman JN. Techniques in regional anaesthesia. Lee's Synopsis of Anaesthesia. 13 ${ }^{\text {th }}$ ed. Elsevier, 2006;401-70.

3. Bubanendran A, Kroin JS. Useful adjuvant for postoperative management. Best Pract Res Clin Anesthesiol. 2007;21:31-49.

4. Sanwal MK, Baduni N, Jain A. Bupivacaine sparing effect of intrathecal midazolam in subarachnoid block for caesarean section. J Obstet Anaesth Crit Care. 2013;3(1):27-31.

5. Al-Mustafa MM, Abu-Halaweh SA, Aloweidi AS, Murshidi MM, Ammari BA, Awwad ZM, et al. Effect of dexmedetomidine added to spinal bupivacaine for urological procedures. Saudi Med J. 2009;30(3):365-70.

6. Frager RJ, Fitzgerald PC. Effect of dexmedetomidine on the MAC of Sevoflurane in adults aged 55-70yrs. J Clin Anesth. 1999;11:466-70.

7. Martin E, Ramsay G, Sum MJ, Ping ST. The role of alpha 2 adrenergic agonist, dexmedetomidine in post surgical sedation in the intensive care unit. J Intensive Care Med. 2000;18:29-34.

8. Coursin DB, Maccioli GA, Dexmedetomidine Curr Opin Crit Care. 2001;7:221-6

9. Shaikh SI, Dattari R. Dexmedetomidine as an adjuvant to hyperbaric spinal bupivacaine for infra-umbilical procedures: A dose related study. Anaesth, Pain Intensive Care. 2014;18(2):180-5.

10. Abdelhamid, S.A. 2013. Intrathecal dexmedetomidine: useful or not? J anesthclin res., volume 4 , issue 3 . 